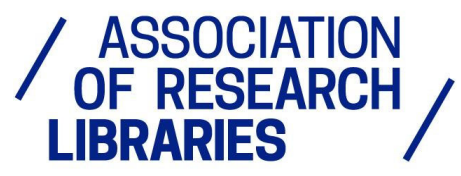

\title{
Library Impact Practice Brief Supporting Bibliometric Data Needs at Academic Institutions
}

Creators: Shannon Gordon, Alison Hitchens

University of Waterloo Library

October 28, 2020

This work is licensed under a Creative Commons Attribution 4.0 International License. 


\section{Issue}

- How can research libraries support their campus community in accessing needed bibliometric data for institutional-level ${ }^{1}$ purposes?

\section{Why It Matters to Research Libraries}

- Academic institutions increasingly need to quantify research impact for a range of internally and externally motivated purposes; for example, to better understand research performance, to benchmark, to demonstrate accountability, to inform strategic decisions, to assess reputation, to secure funding, to support competitive intelligence, etc.

- Research libraries have the specialized knowledge base needed for offering an informed, neutral perspective on this type of data. ("Neutral" refers to the fact that the library does not have a personal stake in the outcome of the needed bibliometric data, such as the associated assessment or evaluation processes.) A unique opportunity exists for research libraries to be a key partner in meeting this growing institutional need.

- It raises the profile of the research library and builds positive, campus-wide relationships among colleagues working closely with research impact issues.

- In A Practical Guide for Informationists: Supporting Research and Clinical Practice, Christopher Belter effectively captures why libraries are positioned to take on this role. ${ }^{2}$ For example:

- Library users are already increasingly asking librarians to provide insight into this specialized area of knowledge Libraries have supported individual faculty members measuring their impact for decades.

- Librarians already have much of the skill set required to support bibliometric data work; librarians understand scholarly communications and have deep expertise in data sources and are aware of disciplinary limitations.

- The trust factor provided by librarians once again speaks to the neutral role that libraries and librarians play in providing access to data.

- Additionally:

- Librarians work with scholars at many points along the research life cycle.

- Librarians have experience in liaising between academic support units and faculties.

While the University of Waterloo Library ${ }^{3}$ has become a recognized campus hub for bibliometrics and research impact (BRI) expertise, success is due to close collaboration with two other units (further described below); this framework has potential applicability to institutions elsewhere. Ultimately, however, flexibility is key, as the bibliometrics "flavor" is influenced by local needs and interests.

By highlighting the established role of the University of Waterloo, a research-intensive Canadian university, ${ }^{4}$ this brief offers a possible method for how other research libraries can support the growing area of bibliometrics. It explores: service background, partners, service providers and 
users, how bibliometric data are used, data sources, key lessons learned (including gaps), and recommended resources.

A combination of close collaboration with campus partners and demonstrating expertise and success has strengthened library relationships, especially with the associate deans for research, and has opened opportunities for further collaboration.

\section{Objectives}

1. To provide an overview of an established framework for research library support of institutional-level bibliometric data and analysis needs at an academic institution

2. To encourage practical collaboration among those knowledgeable about bibliometric data, both within an institution's research library and within other campus units

3. To identify the ways in which bibliometric data is consulted as a data point, based on the experience of one research-intensive university

\section{Background}

The following timeline captures campus interest in bibliometrics at the University of Waterloo. While beginning in 2011, earlier attention was demonstrated by the library through offering workshops on measuring an individual's academic footprint.

- 2011: Campus interest in bibliometric data emerged.

- 2012: The vice president, academic and provost recognized the need for internal expertise in this area by establishing the campus-wide Working Group on Bibliometrics. ${ }^{5}$ This group continues to meet during the academic year with membership from faculty/staff affiliated with all six faculties, ${ }^{6}$ the library, Office of Research (OR), Institutional Analysis and Planning (IAP), and select research centers/institutes.

- 2013: The university's 2013-2018 strategic plan ${ }^{7}$ was unveiled, with the "Transformational Research" theme's primary objective being to "build wider awareness and understanding of Waterloo's research productivity and impact." The plan also stated that "Waterloo will allocate current resources and align future resources to support areas of research where we have the greatest potential for world leadership, including quantum science, water and aging." During the same year, the university approved and funded a new position for a bibliometrics and research impact librarian (BRIL). ${ }^{8}$ The university's subscription to InCites (Clarivate Analytics) began.

- 2015: The BRIL led the library's formal BRI service, with creation of the Research Impact Group (RIG) following shortly after. Chaired by the library, RIG membership included those individuals in Institutional Analysis and Planning and the Office of Research whose portfolio involves elements of research impact. 
- 2016: A subgroup of the Working Group on Bibliometrics published the White Paper: Measuring Research Output through Bibliometrics ${ }^{9}$ with robust campus consultation.

- 2018: The university's subscription to SciVal (Elsevier) began.

- 2019: A subgroup of the Working Group on Bibliometrics compared two major bibliometrics tools and made recommendations on campus subscriptions.

- 2020: A Bibliometrics Community of Practice was formed.

\section{Partners}

- While the library is the day-to-day service hub for bibliometric data needs, Waterloo's framework for supporting institutional bibliometric data needs is firmly rooted in collaboration, and includes three campus units, each having unique research impact expertise:

- The University of Waterloo Library has robust knowledge of bibliometrics, including underlying data sources and expertise in scholarly publishing and search methodology.

- Institutional Analysis and Planning (IAP) ${ }^{10}$ has rich knowledge of key performance indicators and institutional planning activities.

- Office of Research (OR) ${ }^{11}$ has deep knowledge of research funding and the research ecosystem, locally, domestically, and internationally.

- Each partner unit has active membership on the university's Working Group on Bibliometrics and any ad hoc sub-groups, and the Research Impact Group. This ensures that each partner is tuned in to the pulse of campus interest and special projects in this area.

- The library makes it a priority to ensure that partner units are informed of local bibliometric data needs as appropriate and collaborates with partner units as needed. This allows partners to identify trends in data needs, identify requests that relate to projects at the institutional level, and flag strategic or sensitive requests for larger group discussion.

- As partnering with IAP and OR involves ongoing communication and commitment, the library's trusted relationship with these partner units has grown and strengthened over time.

\section{Service Providers and Users}

Waterloo's service model supports the institution's internal bibliometric data needs, with the library being both the administrative lead and day-to-day service hub. While liaison librarians do help faculty members with individual needs for bibliometric data, this type of support is not currently offered as a coordinated service. This is largely due to the human resourcing that would be necessary to provide this service to a large volume of faculty members; further, the library's service model reflects the organization's vision of providing support to meet institutional-level data needs, as well as needs of research centers and research institutes.

\section{Provided Services}

The library currently provides support to the University of Waterloo for: 
- Communicating best practices for conducting responsible research evaluation involving bibliometric data

- Validating bibliometric data of high-profile university rankings monitored by the institution, such as the Times Higher Education (THE) World University Rankings, ${ }^{12}$ and QS Quacquarelli Symonds World University Rankings ${ }^{13}$

- Validating bibliometric data of government-level documentation (such as bibliometric measures used in government funding agreements)

- Customized training and technical support for faculty and staff using bibliometric assessment tools (such as InCites, SciVal), as well as citation-tracking databases (such as Scopus, Web of Science)

- Providing bibliometric data to:

- Benchmark internally and externally

- Identify research areas of strength and areas of opportunity/growth

- Identify research collaborations domestically and internationally

- Support strategic planning (university level and research centers/institutes)

- Provide evidence of accountability (internally and externally)

- Support competitive grant applications

\section{Service Providers}

- The library is the administrative and technical lead for the BRI service; the library is very much the day-to-day service hub for supporting bibliometric data needs.

- Since 2015, the BRIL has been the main contact point for institutional queries relating to bibliometric data. This role reports to the associate university librarian, collections, technology and scholarly communication, and is part of the Library Office department.

- Depending on data needs, individuals in the library's Digital Initiatives department are brought in as consultants to provide programming and other technical support.

- Similarly, liaison librarians may be consulted.

\section{Service Users}

Primary users of the BRI service are:

- Core campus support units supporting elements of research impact, including the library, IAP, and OR

- Other campus support units, including Waterloo International ${ }^{14}$ and University Communications ${ }^{15}$

- Research centers/institutes, ${ }^{16}$ such as the Waterloo Institute for Nanotechnology (WIN $)^{17}$

- Faculties and departments

- Individuals working closely with data at a technical level, such as: data analysts, librarians, research assistants, co-op students, support staff, etc. Individuals in these roles typically receive training on InCites and/or SciVal to support informed use of both the tools and data

- Administrators using bibliometric data to inform decisions, such as high-level administrators (president, vice presidents, university librarian, associate deans of research), directors, managers, and others in decision-making positions 
While some faculty and graduate students have connected with the library for bibliometric data needs, the majority of needs are from individuals directly supporting data needs for their unit as part of their portfolio, and largely represent internal data requirements.

\section{Service Delivery Model}

- The library's service model is largely driven by request. Depending on the request criteria (timeline, actual need, requesting unit, etc.), the library will pursue one of the following approaches:

a. To be the technical lead for pulling/synthesizing the needed bibliometric data

b. To take a train-the-trainer approach to ensure that the requester has the technical skills and knowledge of best practices needed to acquire and work with bibliometric data

- Meetings, consultations, and/or training can occur in one of two ways:

a. In person, whether at the library or elsewhere on campus

b. Virtually via email, phone, or video conferencing software

- Regardless of service delivery mode, library support involves in-depth knowledge and highly customized training sessions, similar to the expert knowledge shared by a liaison librarian during a research consultation.

- Training sessions are highly customized and offer trainees the opportunity to explore a tool while being guided by a local product expert. In addition to hands-on time in the relevant tool(s), training sessions involve preparing training material (typically in MS PowerPoint) to ensure that users have useful, customized technical documentation on file for the future. Training sessions are designed to provide campus colleagues with the technical skills needed to achieve the data goals of their campus unit.

- The library also regularly communicates with vendors and service providers as appropriatefor example, to clarify technical details, report technical issues, share local use cases, share user feedback, etc.

- Ultimately, local needs and stakeholders will influence the service delivery model that is the most appropriate fit for any organization exploring this type of service.

\section{How Bibliometric Data Are Used}

The University of Waterloo uses bibliometric data to meet a range of internal and external needs and requirements. Many of these uses are identified by the university's white paper on bibliometrics: ${ }^{18}$

- To validate university rankings' bibliometric data (QS, THE, etc.)

- To better understand internal research output and impact

- To benchmark internally and externally

- To identify areas of research strength

- To identify emerging areas of research 
- To identify existing and potential research collaborations with academic institutions and industry, domestically and internationally

- To support strategic planning at the institution-level and for research centers/institutes

- To provide evidence of accountability-for example, to meet external funding requirements

- To identify a baseline of research performance for new research groups

- To support competitive grant applications

- To support tenure and promotion packages

While there are certainly other uses of bibliometric data, these are the uses of most interest to Waterloo and often inform strategic decision-making in some way.

\section{Bibliometric Data Points}

A range of bibliometric indicators are available from bibliometric assessment tools, with examples offered below. Such indicators may be explored for the institution as a whole, benchmarked against peer/aspirational institutions, examined within a specific subject area, etc.

- Publication-based indicators: total publications, volume of international collaborations, volume of industry collaborations, etc.

- Citation-based indicators: total citations, percentage of works cited, average number of citations, discipline normalized citation impact, top citation percentiles (1\%, 10\%, etc.), hindex, etc.

- Journal-level indicators: journal normalized citation impact, journal impact factor (JIF), etc.

- Altmetric data indicators: volume of news outlets acknowledging research output, volume of Facebook likes, Tweets, blog postings, etc.

\section{Methodology}

A variety of analysis methodologies exist, ranging from basic to more complex analysis of bibliometric data. The Waterloo service model has traditionally focused on fundamental analyses, such as identifying and monitoring trends over time, identifying highly cited papers, exploring output in top percentiles (for example, top $1 \%$ of cited works), etc. Diving deeper into data analysis, based on bibliometric theory, is certainly possible; some potential examples include: bibliometric network analysis, including collaboration networks/analyses; in-depth topic analysis; and sophisticated statistical analysis of the data. The extent to which an institution can pursue more robust analysis is closely connected to internal bandwidth, expertise, and demand. Regardless of the methodology, transparency of known strengths and known limitations of bibliometric data is vital.

For example, the following two case studies use bibliometrics to better understand research impact. Some units have their own bibliometrics expertise and may simply need to consult with the library if they encounter issues, while other units may work with the library to determine the best approach. 
Case one: A faculty historically did analysis based on journal classification but with a low level of granularity and precision. The faculty changed its methodology to better understand research production of its members, units, and research groups.

- Identified Scopus IDs of all relevant researchers and cleaned IDs as required (for example, merged multiple entries for individual researchers)

- Mapped researchers to their home departments and key research groups

- Imported a list of researchers with Scopus IDs into a bibliometrics tool as a hierarchical entity

- Developed dashboards for summarizing key bibliometric measures and indicators for ongoing analysis at faculty, department or school, and research group levels

- Allowed custom analysis of research outputs by thematic areas or collaborations

Case two: A research center used bibliometrics software to better understand institution-affiliated research in a specific interdisciplinary research area and allow for benchmarking with other research groups.

- Identified relevant researchers at the institution and created a custom hierarchy

- Used a "topics \& topic clusters" feature to analyze output and field-weighted citation impact of affiliated research at the article level

- Examined data over time for the local institution and defined comparator institutions, looking at indicators such as total publications, total citations, and field-weighted citation impact

- Used a collaboration feature to offer insight into collaborators at the institutional, national, and international levels

- Isolated trends in research output by topic

\section{Data Sources}

At the time of writing this document, the University of Waterloo subscribed to several data sources supporting bibliometric data needs, including:

- InCites (Clarivate Analytics)

- SciVal (Elsevier)

- Scopus (Elsevier)

- Web of Science (Clarivate Analytics)

It is important to acknowledge that these are not the only products on the market. Additional product options are shared later in this document. 


\section{Resources Required}

The library provides significant resourcing for this service. While this brief focuses on libraryrequired resourcing, it is certainly true that other campus units also have people whose portfolios include research impact.

\section{People}

a. One bibliometrics and research impact librarian (100\% FTE). This specialist role primarily supports internal, administrative bibliometric data requests from the university.

b. Technical back-up and consultation from the library technology team is available on an ad-hoc basis.

c. Analytical back-up and consultation from the library reporting and assessment analyst is available on an ad-hoc basis.

d. Cross-trained staff who can cover vacations in case of time-sensitive requests

e. Vendor contact point(s) for product subscriptions

f. Occasional MLIS co-op student support for updating library guides and other training materials and to work on small projects. Historically, this has been $30 \%$ of their co-op portfolio.

\section{Skills \& Expertise}

a. Subject knowledge: in-depth understanding of bibliometric data, including indicators, data sources, methodologies, author-level and organization-level identifiers, responsible research evaluation, and awareness of domestic and international BRI trends

b. Technical knowledge: data sources, troubleshooting, methodologies, working with large amounts of data, spot-checking, APIs, programming, and MS Excel. In some instances, it may be most logical to spread technical skills and support across more than one individual.

c. Data management: working with large amounts of data, data cleaning (i.e., author disambiguation), spot-checking, identifying duplicate entries, and troubleshooting missing and/or null values

d. Knowledge of basic statistics: mean (average), median, mode, ranges, outliers, correlation, causation, etc.

e. Communication skills: diplomatic electronic/written/oral communication, and ability to form and maintain positive working relationships, internally and externally (for example, with vendors and peers)

f. Project management: leading special projects, creating project documentation, working with diverse stakeholders, and meeting time-sensitive deadlines

g. Instruction and information literacy: preparing instructional material, delivering inperson/virtual customized training, outreach, and education

h. Institutional knowledge: understanding institutional stakeholders, hierarchies, and decision-making processes

\section{Technical Resources}

a. Software ${ }^{19}$

i. Bibliometric assessment tools, such as InCites, SciVal, and/or Dimensions 
ii. Databases, such as Scopus and/or Web of Science

iii. Altmetric data tools, such as Explorer for Institutions ${ }^{20}$

iv. Spreadsheet programs, such as MS Excel

v. Bibliometric data visualization programs, such as VOSviewer $^{21}$

vi. Other data visualization programs, such as Tableau ${ }^{22}$

vii. Programming languages can assist with data analysis and application programming interface (API) use, such as R and Python.

viii. Many data providers allow programmatic access to data (e.g., the Scopus API).

b. Hardware: personal computer or laptop with large/external monitor

c. Digital storage: file storage to house raw data generated by projects. Due to the sensitive nature of bibliometric data, secure space for data files is critical.

d. Physical space: private meeting space for one-on-one meetings as discussed information is often confidential and sensitive.

4. Gaps

a. Bandwidth: It can be challenging to ensure that bibliometric data needs can be met when key contacts are unavailable (committed to other projects, away, etc.).

b. Data sources: It is not financially possible to subscribe to all data sources that are relevant to bibliometric data needs. However, due to the overlapping nature of features and content, an institution should be able to choose a tool(s) that best meets its priorities.

c. Technical support: Current technical support is ad hoc, which can present challenges in meeting tight deadlines.

d. Supporting individual needs: Current model supports internal, institutional data requests but does not explicitly provide support to individual faculty members. Some of this need is met by liaison librarians.

\section{Lessons Learned}

\section{- Knowledge of Bibliometrics}

- Strategically leverage the bibliometric knowledge that exists across an institution.

- Ideally, at least two individuals should be available as a resource point of contact.

- Access to expert subject knowledge is valuable for validating search methodologies.

- Statistical knowledge offers the opportunity to make data even more meaningful.

- Invest in meaningful opportunities for professional development, domestically and internationally; a positive spin-off effect is how such experiences naturally support long-term institutional networking.

- Encourage service/data requesters to use their internal staff resources to support data cleaning and aggregation, which will free up time for those with more bibliometricspecific knowledge to do the analysis (for example, asking a co-op student to find Scopus IDs for external researchers)

- Communication

- Collaboration, internally and externally, is beneficial, encouraged, and strategic. 
- Diplomatic communication is essential given the sensitive nature of bibliometric data.

- It is essential to communicate data via evidence-based findings and to present a neutral perspective.

- Treat data requests as confidential unless identified as otherwise.

- Maintain a network with colleagues doing similar work at other institutions.

- Establish and maintain positive relationships with vendors.

- Strategic communication is important; success of the University of Waterloo's white paper on bibliometrics ${ }^{23}$ was very much the result of an intentional, campus-wide consultation process, and represented work of a cross-campus working group.

\section{- Institutional Readiness}

- A research library's service model in this area will be directly influenced by institutional readiness. As readiness may change over time, there may be future opportunities for the service model to evolve as new needs and interests emerge.

- Institutional readiness has played a central role in Waterloo's successful model. This is evidenced by the university establishing a formal Working Group on Bibliometrics, as well as the common ground built through the university's white paper on bibliometrics.

\section{- Search Methodologies}

- Often, there is no single "perfect" methodology for acquiring needed bibliometric data; rather, there are several possibilities. The pros and cons of possible methodologies must be considered to determine the most appropriate route. Developing a robust methodology involves a process similar to building an advanced search string.

- Methodological transparency is critical, as is identifying known limitations.

- Working with bibliometric data is labor-intensive and should not be rushed.

- Leverage the technical expertise of vendors to clarify technical workings of tools and to fine-tune methodologies as needed.

\section{- Data Set Weaknesses}

- Major data sets often best support STEM disciplines due to research outputs in these disciplines being focused on journal publications, and the related known bias of journal indexes.

- More investigation of alternative metrics is needed to capture nontraditional outputs and disciplines without strong representation in common data sets.

- Topic areas in data sets do not map cleanly to research areas of departments and faculties; for example, the topic "mathematics" does not map directly to a Faculty of Mathematics. Therefore, being able to create unique groups aids in this analysis.

- Not all research that is published and has impact is cited-for example, research that influences public policy, such as taxation. 


\section{- Producing Final Data Set}

- Even when bibliometric data is automatically extracted from a data source, it is often necessary to spot-check the data for quality assurance purposes (for reasons of name ambiguity, missing/null values, outliers, etc.).

○ Data spot-checking, cleaning, and validation is labor-intensive; it is necessary to allocate time for this phase when planning project work.

- Balancing this labor-intensity with the time-sensitivity of requests requires negotiation around deadlines and priorities.

- Ensure the data set source is always cited and take time to describe why this is important when working with partners.

\section{- Ethical Considerations}

- Due to known inappropriate uses, approach requests for individual-level ${ }^{24}$ and discipline-level ${ }^{25}$ bibliometric data with extreme caution.

- Discourage decisions, such as promotion and tenure, being made solely based on bibliometric data; rather, encourage working from a basket of measures, including peer review, to guide decision-making at all levels.

- Take the time to acknowledge that "impact" remains subjective.

- Be aware of good practices in bibliometrics as recommended by the Leiden Manifesto ${ }^{26}$ and the San Francisco Declaration on Research Assessment. ${ }^{27}$

- Value

- Feedback, received informally and formally, indicates that the library's service model for supporting institutional-level bibliometric data needs is highly valued by a range of internal campus stakeholders. For example, it:

- Raises the profile of the research library by centralizing bibliometric data knowledge

- Builds positive, campus-wide relationships among colleagues working closely with research impact issues. If not for the formal structure provided by this service model, such relationships may not exist.

- Provides the campus with a main contact point for questions relating to bibliometric data, an invaluable support for purposes of data validation, strategic planning, supporting competitive grant applications, and providing evidence of accountability

- Provides customized, point-of-need support to campus units requiring bibliometric data

- Provides the campus with a local trainer for tools like InCites and SciVal

- Feedback also indicates that the library's service model is highly valued by a range of external colleagues. For example, it:

- Builds valuable and strategic relationships external to the institution, as this area of research librarianship remains small and close knit, even globally 
- Has resulted in Waterloo being contacted by several external institutions, domestically and internationally, interested in establishing this type of service at their home institution

- Provides opportunities for Waterloo to share lessons learned and local use cases at conferences and product user forums

Belter effectively describes the value of libraries providing this type of service:

"The benefits of bibliometrics to libraries are clear. By providing services directly to administrators and policy makers, bibliometrics programs increase the visibility and prestige of the library to a key stakeholder group that is traditionally underserved by libraries...Most importantly, bibliometrics adds value to the services of the library. It allows the library to adapt to the changing information needs of its customers and provide new kinds of services that contribute directly to furthering the institution's research mission." 28

\section{Recommendations for the Future}

- Existing partnerships and collaborations should continue to be nurtured and expanded.

- The service model should continue to be library-led.

- Determine appropriate staffing capacity within the library, including key contact point(s), programming support, and the role of liaisons librarians; also determine the appropriate level of training for library staff, depending on their support role.

- Continue to actively monitor evolution of other tools specializing in bibliometric data.

- Explore full potential of the APIs of current data sources.

- Further explore visualization possibilities for bibliometric data.

- Maintain awareness of any developments that would impact service models, such as domestic and international trends in the areas, understanding the impact of interdisciplinary/multidisciplinary research, and better understanding the impact of scholarly output in non-STEM areas, particularly in the arts and humanities.

\section{Resources}

\section{Examples of BRI Services}

This list, while not exhaustive, identifies a range of existing BRI services, which may help to inform the development, or reviewing, of service models in this area. Of course, the local institution's vision and available resourcing will determine the most appropriate BRI service program. 


\section{Canada}

- $\quad$ Bibliometric \& Research Impact Services, University of Waterloo ${ }^{29}$

- Also: BRI Librarian ${ }^{30} \&$ Working Group on Bibliometrics $^{31}$

- $\quad$ Research Impact Team, University of Alberta ${ }^{32}$

- Research Impact \& Researcher Identity, University of Toronto ${ }^{33}$

\section{United States}

- $\quad$ Metrics \& Impact Core, Northwestern University ${ }^{34}$

- Bibliometric Services Program, National Institutes of Health ${ }^{35}$

- $\quad$ Author Analytics and Support, Washington University School of Medicine in St. Louis ${ }^{36}$

- $\quad$ Citation and Research Impact Services, Weill Cornell Medicine ${ }^{37}$

\section{Europe}

- Bibliometrics and Publication Strategies, University of Vienna ${ }^{38}$

- Research, Quality and Impact Team, University of Sussex ${ }^{39}$

- Bibliometrics Service, Imperial College London ${ }^{40}$

- Also: "Book a One to One"

- This article may also be a useful reference point: "Research Evaluation Support Services in Biomedical Libraries." 42

- The Competency Model for Bibliometric Work ${ }^{43}$ may also be useful for developing job descriptions.

\section{Continuing Education \& Professional Development}

This alphabetical list highlights several opportunities for learning more about the complex BRI landscape.

- $\quad$ Altmetrics Conference ${ }^{44}$

- $\quad$ Canadian Bibliometrics \& Research Impact Community (BRIC) Conference $^{45}$

- $\quad$ CWTS Training \& Education ${ }^{46}$

- European Summer School for Scientometrics (ESSS) ${ }^{47}$

- INORMS Research Evaluation Working Group ${ }^{48}$

- LIS Bibliometrics Annual Event ${ }^{49}$

- LIS-Bibliometrics email discussion list ${ }^{50}$

- NIH Library's Bibliometrics Training Series ${ }^{51}$

- Research Impact Services Google Group ${ }^{52}$

- $\quad$ Responsible Use Guides ${ }^{53}$

- Using InCites Responsibly: A Guide to Interpretation and Good Practice ${ }^{54}$

- Using SciVal Responsibly: A Guide to Interpretation and Good Practice ${ }^{55}$ 
- Vendors: Individuals in formal BRI positions are encouraged to pursue training opportunities delivered by the vendor of BRI data sources. Doing so will build and strengthen local knowledge for relevant tools, which is critical for key BRI contacts at an institution.

\section{Recommended Reading}

Several practical readings are highlighted below; individuals are also encouraged to explore new information sources to ensure the greatest awareness of the BRI world as it is constantly evolving.

Belter, Christopher W. "Providing Meaningful Information: Part B-Bibliometric Analysis.” In A Practical Guide for Informationists: Supporting Research and Clinical Practice, edited by Antonio P. DeRosa, 37-38. Cambridge, MA: Elsevier/Chandos, 2018.

The Bibliomagician (blog). LIS Bibliometrics. https://thebibliomagician.wordpress.com/. (See also: "Further Reading." https://thebibliomagician.wordpress.com/further-reading/.)

Declaration on Research Assessment (website). Accessed June 10, 2021. https://sfdora.org/.

Federation for the Humanities and Social Sciences. Approaches to Assessing Impacts in the Humanities and Social Sciences. Ottawa: Federation for the Humanities and Social Sciences, 2017. https://www.ideas-idees.ca/sites/default/files/impact_report_en_final.pdf.

Hicks, Diana, Paul Wouters, Ludo Waltman, Sarah de Rijcke, and Ismael Rafols. "The Leiden Manifesto for Research Metrics.” Nature 520 (April 23, 2015): 429-431. https://www.nature.com/news/polopoly_fs/1.17351!/menu/main/topColumns/topLeftColumn /pdf/520429a.pdf.

National Information Standards Organization. Outputs of the NISO Alternative Assessment Metrics Project. Baltimore, Maryland: National Information Standards Organization, 2016. https:/groups.niso.org/apps/group_public/download.php/17091/NISO\%20RP-252016\%200utputs\%20of\%20the\%20NISO\%20Alternative\%20Assessment\%20Project.pdf.

National Institutes of Health Library. "Additional Reading." Accessed June 10, 2021. https://www.nihlibrary.nih.gov/services/bibliometrics/bibliometrics-trainingseries/additional-reading.

Parks, Sarah, Daniela Rodriguez-Rincon, Sarah Parkinson, and Catriona Manville. The Changing Research Landscape and Reflections on National Research Assessment in the Future. Santa Monica, California: RAND Corporation, 2019. https://re.ukri.org/sectorguidance/publications/research-by-rand-europe/.

Snowball Metrics (website). Accessed June 10, 2021. https://snowballmetrics.com/. 
University of Waterloo Working Group on Bibliometrics. White Paper: Measuring Research Output through Bibliometrics. Waterloo, Ontario: University of Waterloo, Winter 2016.

https://doi.org/10.13140/RG.2.1.3302.5680. (Also see the companion guide: University of Waterloo Library. "Bibliometrics \& Measuring Research Output: Overview." Accessed June 10, 2021. https://subjectguides.uwaterloo.ca/bibliometrics.)

Wilsdon, James, Liz Allen, Eleonora Belfiore, Philip Campbell, Stephen Curry, Steven Hill, Richard Jones, et al. The Metric Tide: Report of the Independent Review of the Role of Metrics in Research Assessment and Management. Stoke Gifford, UK: Higher Education Funding Council for England, 2015. https://doi.org/10.13140/RG.2.1.4929.1363.

\section{Acknowledgments}

As a practice brief is largely influenced by experience, it is critical that we thank the numerous internal and external reviewers who provided thoughtful feedback during the editing process. All comments strengthened this document and helped create something of relevance to the wider community. A special thank you to Laura Bredahl, bibliometrics and research impact librarian at University of Waterloo, for updates to current practice. Lastly, thank you to the ARL staff who provided support and suggestions for this project.

\section{Endnotes}

${ }^{1}$ The service model was intentionally developed to support known bibliometric data needs at the institutional level, rather than individual-level needs of faculty members. Scoping the service this way reflected the organization's vision of providing support for institutional-level data needs, including the needs of research centers and institutes affiliated with the institution. While liaison librarians certainly help faculty members with individual needs for bibliometric data, this support is not currently offered as a coordinated service.

${ }^{2}$ Christopher W. Belter, "Providing Meaningful Information: Part B-Bibliometric Analysis," in A Practical Guide for Informationists: Supporting Research and Clinical Practice, ed. Antonio P. DeRosa (Cambridge, MA: Elsevier/Chandos, 2018), 37-38.

${ }^{3}$ University of Waterloo Library (website), accessed January 23, 2020, https://lib.uwaterloo.ca/web/index.php.

4 “Our Members," U15 Group of Canadian Research Universities, accessed December 16, 2020, https://u15.ca/our-members.

5 "Bibliometrics," University of Waterloo, accessed December 16, 2020, https://uwaterloo.ca/institutionalanalysis-planning/reports/bibliometrics.

6 "Faculties and Academics," University of Waterloo, accessed December 16, 2020, https://uwaterloo.ca/faculties-academics. 
7 “Strategic Plan 2013-2018," University of Waterloo, accessed December 16, 2020, https://uwaterloo.ca/strategic-plan-2013-2018/strategic-plan-2013-2018.

8 “Job Description: Bibliometrics and Research Impact Librarian," University of Waterloo, accessed December 16, 2020, https://hr.uwaterloo.ca/.jd/00006514.pdf.

${ }^{9}$ University of Waterloo Working Group on Bibliometrics, White Paper: Measuring Research Output through Bibliometrics (Waterloo, Ontario: University of Waterloo, Winter 2016), https://doi.org/10.13140/RG.2.1.3302.5680.

10 "Institutional Analysis \& Planning," University of Waterloo, accessed December 16, 2020, https://uwaterloo.ca/institutional-analysis-planning/.

11 “Research,” University of Waterloo, accessed December 16, 2020, https://uwaterloo.ca/research/.

12 “World University Rankings,” Times Higher Education (THE), accessed January 21, 2021, https://www.timeshighereducation.com/world-university-rankings.

13 “University Rankings," QS Quacquarelli Symonds, accessed January 21, 2021, http://www.iu.qs.com/university-rankings/.

14 "Waterloo International," University of Waterloo, accessed January 21, 2021, https://uwaterloo.ca/international/.

15 "University Communications," University of Waterloo, accessed January 21, 2021, https://uwaterloo.ca/university-communications/.

16 "Research: Centres and Institutes," University of Waterloo, accessed January 21, 2021, https://uwaterloo.ca/research/research-excellence/senate-approved-centres-and-institutes.

17 "Waterloo Institute for Nanotechnology," University of Waterloo, accessed January 21, 2021, https://uwaterloo.ca/institute-nanotechnology/.

${ }^{18}$ Working Group on Bibliometrics, White Paper.

${ }^{19}$ While Waterloo may not currently use all of the identified resources, they are relevant to organizations interested in setting up a similar service, with actual product use directly influenced by local needs, local budget, etc.

20 “Explorer for Institutions,” Altmetric, accessed January 23, 2020, https://www.altmetric.com/products/explorer-for-institutions/.

21 "Welcome to VOSviewer," Centre for Science and Technology Studies, Leiden University, accessed June 10, 2021, https://www.vosviewer.com/.

${ }^{22}$ Tableau (website), accessed June 10, 2021, https://www.tableau.com/.

${ }^{23}$ Working Group on Bibliometrics, White Paper.

24 "Bibliometrics \& Measuring Research Output: Individual Data," University of Waterloo Library, accessed June 10, 2021, https://subjectguides.uwaterloo.ca/bibliometrics/individualdata. 
25 "Bibliometrics \& Measuring Research Output: Discipline Data," University of Waterloo Library, accessed June 10, 2021, https://subjectguides.uwaterloo.ca/bibliometrics/disciplinedata.

${ }^{26}$ Leiden Manifesto for Research Metrics (website), accessed June 10, 2021, http://www.leidenmanifesto.org/.

${ }^{27}$ Declaration on Research Assessment (website), accessed June 10, 2021, https://sfdora.org/.

${ }^{28}$ Belter, "Providing Meaningful Information," 44.

29 “Bibliometric and Research Impact Services," University of Waterloo Library, accessed June 10, 2021, https://uwaterloo.ca/library/services/bibliometric-and-research-impact-services.

${ }^{30}$ Bibliometrics and Research Impact Librarian Job Description, University of Waterloo, accessed June 10, 2021, https://hr.uwaterloo.ca/.jd/00006514.pdf.

31 "Bibliometrics," University of Waterloo.

32 "Research Impact," University of Alberta Library, accessed June 10, 2021, https://www.library.ualberta.ca/services/research-impact.

33 “Research Impact \& Researcher Identity," University of Toronto Libraries, accessed June 10, 2021, https://guides.library.utoronto.ca/researchimpact.

34 “Metrics \& Impact Core," Galter Health Sciences Library \& Learning Center, Northwestern University, accessed June 10, 2021,

https://galter.northwestern.edu/galterguides?url=https\%3A\%2F\%2Flibguides.galter.northwestern.edu\%2F MIC.

35 "Bibliometric Services," National Institutes of Health Library, accessed June 10, 2021, https://www.nihlibrary.nih.gov/services/bibliometrics.

36 "Author Analytics and Support," Bernard Becker Medical Library, Washington University School of Medicine in St. Louis, accessed June 10, 2021, https://becker.wustl.edu/services/author-analytics-andsupport/.

37 "Scholarly Profile Management and Publications Reporting," Samuel J. Wood Library, Weill Cornell Medicine, accessed June 10, 2021, https://library.weill.cornell.edu/research-support/scholarly-profilemanagement-and-publications-reporting.

38 "Bibliometrics at Vienna University," University of Vienna, accessed June 10, 2021, https://bibliothek.univie.ac.at/bibliometrie/en/.

39 "Information and Support for Researchers,” University of Sussex, accessed June 10, 2021, http://www.sussex.ac.uk/staff/research/rqi/rqi_information_and_support.

40 “Bibliometrics," Imperial College London, accessed June 10, 2021, https://www.imperial.ac.uk/researchand-innovation/support-for-staff/scholarly-communication/bibliometrics/.

41 "Book a One to One," Imperial College London, accessed June 10, 2021, https:/www.imperial.ac.uk/research-and-innovation/support-for-staff/scholarlycommunication/bibliometrics/book-a-one-to-one/. 
42 "Research Evaluation Support Services in Biomedical Libraries," Journal of the Medical Library Association 106, no. 1 (2018): 1-14, https://www.ncbi.nlm.nih.gov/pmc/articles/PMC5764574/.

43 "Competency Model for Bibliometric Work," The Bibliomagician (blog), LIS-Bibliometrics Committee, accessed June 10, 2021, https://thebibliomagician.wordpress.com/competencies/.

44 7:AM Altmetrics Conference, accessed June 10, 2021, https://www.altmetricsconference.com/.

${ }^{45}$ Bibliometrics and Research Impact Community Conference, accessed June 10, 2021, https://www.bricconference.ca/.

46 “Training \& Education," Centre for Science and Technology Studies (CWTS), University of Leiden, accessed June 10, 2021, https://www.cwts.nl/education.

${ }^{47}$ European Summer School for Scientometrics, accessed June 10, 2021, https://esss.info/.

48 “About the INORMS Research Evaluation Group,” INORMS, accessed June 10, 2021, https://inorms.net/research-evaluation-group/.

49 "Conferences and Events," The Bibliomagician (blog), LIS-Bibliometrics Committee, accessed June 10, 2021, https://thebibliomagician.wordpress.com/conferences-and-events/.

50 “LIS-BIBLIOMETRICS Home Page,” JISCMail, accessed June 10, 2021, https://www.jiscmail.ac.uk/cgibin/webadmin?A0=LIS-BIBLIOMETRICS.

51 "Bibliometrics Training Series," National Institutes of Health Library, accessed June 10, 2021, https://www.nihlibrary.nih.gov/services/bibliometrics/bibliometrics-training-series.

52 “Research Impact Services,” Google Groups, accessed June 10, 2021, https://groups.google.com/g/resimpact?pli=1.

53 “The Responsible Use Guides,” The Bibliomagician (blog), LIS-Bibliometrics Committee, https://thebibliomagician.wordpress.com/the-responsible-use-guides/.

${ }^{54}$ Andrew Gray and Robyn Price, Using InCites Responsibly: A Guide to Interpretation and Good Practice (January 13, 2020), https://doi.org/10.25561/75946.

${ }^{55}$ Ian Rowlands, Using SciVal Responsibly: A Guide to Interpretation and Good Practice (2020), https://repository.lboro.ac.uk/articles/educational_resource/Using_SciVal_responsibly_a_guide_to_interpre tation_and_good_practice/11812044. 